\title{
RESENHA
}

JASMIN, M. G.; FERES Jr., J. (Org.) História dos conceitos: debates e perspectivas. Rio de Janeiro: Editora PUC-Rio; Loyola; IUPERJ, 2006. 174 p.

Diogo da Silva Roiz*

No Brasil, ainda são escassos estudos que tomam por base a "história dos conceitos", a Begriffsgeschichte, que ganhou forma na Alemanha, principalmente com os trabalhos de Reinhart Koselleck, porque dificuldades "derivadas da pouca tradição com a língua alemã e do vínculo mais forte da historiografia acadêmica brasileira com os desenvolvimentos metodológicos, teóricos e práticos de franceses, ingleses, italianos e norte-americanos são motivos para essa fraca recepção" (2006, p. 21) da historiografia alemã no Brasil, ressaltarão os organizadores desta coletânea.

A "história dos conceitos", desde a década de 1980, é uma abordagem conhecida e respeitada mundialmente porque "manifesta sua vocação de, simultaneamente, identificar as continuidades nas camadas de significados de determinados conceitos e estabelecer a novidade histórica de seus usos determinados" (p. 30). Essa característica foi salientada, primeiro, em função da publicação (dos volumes do dicionário dos conceitos) da obra coletiva, em nove volumes (editados entre 1972 e 1992), dos Conceitos Históricos Fundamentais. Léxico histórico da língua politica e social na Alemanha (a Geschichtliche Grundbegriffe), que cobrem 120 conceitos (que surgiram ou sofreram mudanças fundamentais entre 1750 e 1850), em pouco mais de sete mil páginas. Depois, por causa do pioneirismo deste empreendimento coletivo, levado a cabo por Reinhart Koselleck, Otto Brunner e Werner Conze, que inovou a historiografia mundial e inspirou

\footnotetext{
* Doutorando em História pela UFPR, bolsista do CNPq. Mestre em História pela Unesp, Campus de Franca. Professor da UEMS, em afastamento integral para estudos. E-mail: simoneediogo@hotmail.com
} 
diversas iniciativas semelhantes em vários países. E ainda, da própria contribuição individual de Koselleck, para o reconhecimento desta linha investigativa na Alemanha e no mundo.

Foi justamente percebendo essa lacuna metodológica (vale destacar que a obra de Koselleck só começou a ser editada no Brasil em 1999, com a publicação de Crítica e crise, e a sua edição original alemã é de 1959), que Marcelo Jasmin e João Feres Júnior (praticantes dessa abordagem desde o período em que produziram suas teses) tiveram a iniciativa de publicar este livro, reunindo dois importantes momentos da divulgação desta abordagem metodológica em outros países. E que ocorreu em compasso com as discussões sobre a abordagem collingwoodiana "para o estudo da história do pensamento político, anteriormente designada como Escola de Cambridge", por ter lá se originado, e ainda agrupar alguns de seus principais representantes, como Quentin Skinner e John G. A. Pocock. Além disso, buscou-se com essa iniciativa também demonstrar as aproximações entre essas duas abordagens, que possuem grandes semelhanças, e fortes diferenças teóricas e metodológicas, considerando que na "relação complexa entre conceitos e realidade [...] a separação entre linguagem e história não implica a recusa [...] do caráter lingüístico constitutivo da realidade social e política, mas a busca de um modelo teórico no qual os significados lingüísticos criam, ao mesmo tempo em que limitam, as possibilidades da experiência política e social" (p. 27), acrescentará os organizadores, na introdução do livro.

O livro, História dos conceitos, portanto, agrupa os debates produzidos em 1992, durante um Simpósio patrocinado pelo Instituto de História Germânica, de Washington D. C., nos Estados Unidos, que marcou a publicação do último volume do dicionário de Conceitos Históricos Fundamentais, contou com a participação de Reinhart Koselleck e reuniu os textos de mais outros cinco profissionais, a saber: Melvin Richter, James van Horn Melton, Donald Kelley, Gabriel Motzkin e John Pocock. $\mathrm{O}$ segundo momento que o livro procurou circunstanciar, foi agrupando três entrevistas concedidas 12 anos após aquele simpósio (de 1992), por Melvin Richter (que havia organizado o evento), Kari Palonen "durante a VII Conferência Internacional de História dos Conceitos, ocorrida em julho de 2004 no campus de Ipanema da Universidade Cândido Mendes" 
(p. 10), no Rio de Janeiro (e os resultados do encontro foram publicados em 2007, também pela Editora Loyola, com o título: História dos conceitos: diálogos transatlâticos), e a última entrevista de Reinhart Koselleck oferecida (poucos meses antes de sua morte em fevereiro de 2006) a Javier Fernández Sebastián e Juan Francisco Fuentes, "na tarde de 5 de abril de 2005", na cidade de Madri e publicada, em homenagem ao autor, na Revista de Libros entre março e abril de 2006. Nela o autor indicaria que:

Creio [...] que as experiências vão além da sua interpretação lingüística, mas é certo que para os que reduzem tudo à linguagem, a concentração exclusiva do estudo de certos conceitos básicos [...] poderia provocar o silêncio de outras experiências. Essa abordagem poderia limitar indiretamente a implicação social daquilo que poderíamos descobrir através de qualquer série de conceitos básicos e daquilo que seria silenciado ou oculto por eles (FERES; JASMIN, 2006, p. 167).

Assim, Reinhart Koselleck (1923-2006), resumiria sua discórdia com a "virada linguística" norte-americana e a hermenêutica de HansGeorg Gadamer (1900-2002) na Alemanha. De acordo com ele:

[...] a linguagem é sempre ambígua, ao mesmo tempo receptiva e reprodutiva, porque por um lado indica as mudanças sociais e, por outro, a própria linguagem é um fator essencial que permite tomar consciência dessas mudanças na realidade. Gadamer não aceitava esta ambigüidade da linguagem. Para ele, que seguia os passos de Heidegger, a linguagem trazia com ela, implícita, a totalidade da experiência. É indubitável que, ao traduzir muitos conceitos da língua grega à linguagem filosófica alemã, a filosofia hermenêutica de Gadamer fez da linguagem a chave de toda a realidade humana; um argumento muito forte, mas, para mim, como historiador, impossível de aceitar como a única e exclusiva verdade. Como historiador, não posso manter-me apenas no nível lingüístico; preciso me ocupar também do que (lingüisticamente) poderia ser dito (FERES; JASMIN, 2006, p. 169).

Os próprios entrevistadores, naquela ocasião disseram que a maior contribuição do autor, com a "história dos conceitos", foi investigar 
exaustivamente "a história como sucessão de acontecimentos, a história como atividade intelectual inerente ao ser humano, e sobretudo, a história como experiência existencial e dimensão iniludível, constitutiva da modernidade" (p. 135). Esta entrevista, como dito, foi acrescentada ao livro História dos conceitos, que foi organizado por Marcelo Gantus Jasmin e João Feres Júnior, com vistas a divulgar esta abordagem no Brasil (e as suas diferenças e aproximações com o enfoque collingwoodiano, da interpretação "contextualista" inglesa, que tem em Quentin Skinner e John Pocock seus principais praticantes), justamente num momento em que se expande para várias partes do mundo. Esse sucesso teve origem num empreendimento editorial iniciado na década de 1970, entre Koselleck e Werner Conze (1910-1986) e Otto Brunner (1898-1982), em que procuraram elaborar um dicionário de Conceitos Históricos Fundamentais. Léxico Histórico da Língua Política e Social na Alemanha, cobrindo especialmente, o período de 1750 a 1850, no qual Koselleck dirá que será o momento em que se formaram as principais mudanças léxicas e conceituais que darão forma a Modernidade, por que "a linguagem europeia (nas suas diversas expressões) sofreu um processo radical de transformação que revela e configura a ultrapassagem dos fundamentos da sociedade aristocrática", como bem lembrará Jasmin (em KOSELLECK, 2006, p. 10). Iniciada em 1972, com a publicação do primeiro volume, de uma série de nove (o último de índices e notas), que será concluída em 1992, a obra será verdadeiramente um marco teórico na história da historiografia.

A obra de Koselleck, nesse sentido, se apresentará como uma das bases, e também como um complemento, àquele empreendimento editorial coletivo. Já em 1959, ao lançar sua (famosa) tese Crítica e crise. Uma contribuição a protogênese do mundo burguês (1999), o autor irá demonstrar "como a formação da 'crítica' ilustrada e da 'sociedade civil' provocariam a 'crise' final do Antigo Regime e a derrocada do Absolutismo como forma legítima de poder político" (KOSELLECK, 2006, p. 9), nas palavras de Marcelo Jasmin (à apresentação brasileira de seu livro Futuro Passado). Em 1965, ao estudar a reforma e a revolução no período de 1791 a 1848, em sua tese de habilitação (publicada em 1967), este dará continuidade, e maior densidade, aos seus trabalhos dos anos 50. Com a publicação de Futuro passado: contribuição a semântica dos tempos históricos, 
em 1979, este irá demonstrar teoricamente as principais características da "história conceitual" (e que justificavam o empreendimento editorial coletivo iniciado, poucos anos antes), por meio da análise semântica das diferentes formas de apreensão do tempo e da história, na historiografia europeia, tendo em vista que a "hipótese que se apresenta aqui é a de que, no processo de determinação da distinção entre passado e futuro, ou, usando-se a terminologia antropológica, entre experiência e expectativa, constitui-se algo como um "tempo histórico" e as "análises semânticas aqui apresentadas não têm por objetivo primeiro um estudo de caráter lingüístico-histórico", mas sim "elas pretendem investigar a constituição lingüística das experiências temporais, ali onde elas se manifestam" (2006, p. 16 e 17).

Não se deve perder de vista que, o contexto no qual irá surgir esta obra, é o do início do "revisionismo" da historiografia alemã, no qual se procurará rever a história do Holocausto, proporcionado na Segunda Guerra Mundial (1939-1945), durante o período em que Adolf Hitler (1889-1945) esteve no poder (1933-45). Para uma parte significativa da "intelectualidade" alemã, aquele momento causou uma verdadeira "crise de consciência histórica" no povo alemão, e para a própria "sociedade europeia". Um dos desdobramentos interpretativos daquele movimento revisionista, se amparando tanto na "virada linguística", quanto na interpretação "pós-moderna" da sociedade, será justamente o de questionar a própria existência do "Holocausto" na história europeia. Tendo em vista que, se a história "era pura e simplesmente" um campo interpretativo, no qual as fontes apenas faziam parte de um "efeito de verdade", apresentado pela "narrativa histórica", era necessário apenas se revisitar as fontes e as narrativas, para em seu lugar, serem impostas outras. A obra de Koselleck foi contrária a interpretação "revisionista" sobre a história e os fundamentos da sua escrita.

Esse movimento interpretativo é facilmente observado pelos quatro primeiros ensaios, do primeiro momento do debate, elaborados para o congresso de 1992. Nos comentários de Pocock (quinto) e Koselleck (sexto ensaio), aos quatro textos iniciais, oferece uma verdadeira radiografia tanto da "história conceitual" alemã quanto do "contextualismo" inglês. Para Pocock: 
[...] uma linguagem ou um discurso é, no uso que eu faço, e naquele que Skinner e outros, uma estrutura complexa que abrange um vocabulário, uma gramática, uma retórica e um conjunto de usos, pressupostos e implicações, que existem juntos no tempo e são empregáveis por uma comunidade semi-específica de usuários de linguagem para propósitos políticos, que permite, e por vezes se prolonga até, a articulação de uma visão de mundo ou de uma ideologia (p. 83-4). [...] [uma segunda questão importante] é aquela suscitada pela afirmação de Quentin Skinner de que não é possível, estritamente falando, que se escreva uma história dos conceitos. Tal como entendo Skinner neste ponto, ele está dizendo que a história a ser escrita é a dos fenômenos da linguagem, das palavras e de seus usos, e que as cargas conceituais que carregam (ele não está, é claro, negando a noção de que um conceito significa algo) não podem ser destacadas da história da linguagem e talhadas para possuírem suas próprias histórias independentes (p. 89).

Em relação ao quê, Koselleck procurará responder que:

Posto metaforicamente, os conceitos são como junções ligando a linguagem e o mundo extralingüístico. [...] Metodologicamente, sustento que um tal purismo epistemológico é exigido para qualquer análise adequada de como a linguagem está entrelaçada aos contextos nos quais funciona. Até este ponto, um historicismo rigoroso que registre a não-convertibilidade do que é articulado pela linguagem é a precondição de toda análise conceitual (100-1).

\section{E ainda:}

Toda palavra e todo conceito têm, portanto, um impulso diacrônico contra o qual qualquer um que busque um novo significado precisa operar. Ainda, o que é novo só pode ser compreendido pela primeira vez por causa de algum traço recorrente, alguma referência a um significado aceito, não questionado anteriormente. Mas é este aspecto da linguagem que nos permite falar de algumas idéias durando no tempo (p. 102). [...] Um discurso requer conceitos básicos para expressar o que está falando. E uma análise dos conceitos demanda o conhecimento tanto dos contextos lingüísticos como dos 
extralingüísticos, incluindo aqueles fornecidos pelos discursos. Só através de um tal conhecimento do contexto pode o analista determinar quais são os múltiplos significados de um conceito, seu conteúdo, importância e a extensão em que é disputado (p. 104).

O que pode se dizer, com isso, é que a "história conceitual fornece indicadores de como a história política e social não se desenrola apenas em eventos únicos, mas pode também se repetir em estruturas análogas" (p. 106).

Portanto, a publicação desta obra, quanto a do evento de 2004, cujos resultados saíram em: História dos conceitos: diálogos transatlânticos, em 2007, podem e devem ser saudados como uma fértil abertura da historiografia brasileira para outros campos e abordagens, que poderão colaborar não apenas com a sua renovação, mas também com a produção de trabalhos que tenham em vista questões pouco discutidas, ou se o foram, poder reconsiderá-las sobre outras perspectivas.

Data de registro: 08/09/09

Data de Aceite: 08/12/09 